\title{
It's entrepreneurship, not enterprise: Ai Weiwei as entrepreneur
}

Daniel Hjorth and Robin Holt, both Copenhagen Business School and Nottingham Business School

dh.mpp@cbs.dk_rh.mpp@cbs.dk

Opening

Encomiums to enterprise have never been more fulsome and frequent than at present; the baleful economic effects of financial crisis will be countered by the rise of new ventures, energetic, virtuous even. In the UK Prime Minister Cameron has been especially enthusiastic. In his 201 I Conservative Party speech he was asserting "At its beating heart this is still a party of start-ups, go-getters, risk-takers", going on to argue that, with the public purse empty, the only strategy for recovery were policies that release the innovative ingenuity and persistence of the small firm sector, allowing entrepreneurs to "roll up their sleeves" and help restore economic fortunes.

On the surface come obvious objections to the association of enterprise and economic and social recovery. Was it not precisely enterprise and risk-taking that initiated and deepened the crisis? Yet as with Cameron's agenda, Kenny and Scriver (20I2) note how Eire, a country scoured by its almost hubristic enthusiasm for the innovations offered by structured finance, is also invoking an enterprise agenda to effect almost saviour-like recovery. We find more critical discussions of enterprise-led recovery in Denmark (Sørensen (2008), Finland (Erkkila, 1996), Norway (Ure, 20 I0), Canada (Campbell, 2004), and Sweden (Hjorth, 2003).

Our paper investigates the obvious and easy association of enterprise and entrepreneurship. We do so by focusing on what is meant by social as well as 
economic good in acts of value creation, which brings us to the field of social entrepreneurship. We argue enterprise is only synonymous with entrepreneurship insofar as it empties it of what is social by encouraging an individualistic relationship with commercial value creation. Under the aegis of enterprise, entrepreneurial value accrues in the form of possession, earnings and assets flowing to those demonstrating efficient and effective economic behavior; earnings follow the effort of individuals willing to seize opportunity, irrespective of wider social consideration. If we understand entrepreneurship socially, however, and consider the social as more than something bolted onto entrepreneurship we understand the entrepreneur as she or he whose creativity enhances the relational capacity to act, and so enriches the social condition in terms of possibility. Rather than a seizing of opportunity, entrepreneurship becomes a generosity of action opening up possibility without known ends. To illustrate our argument we use the Chinese artist $\mathrm{Ai}$ Weiwei, notably his Sunflower Seeds project exhibited at the Tate Modern gallery in London, 2010, arguing that artistic practice in Weiwei's case reveals an entrepreneurial concern with acknowledging prevailing habits and norms in ways that bring them into a questionability in a transformative way, offering possibilities for new value-creation (cf. George, McGahan, and Prabhu, 20 I2).

\section{Enterprise}

The category enterprise describes the institutional association of specific commercial forms (ventures, markets) with human qualities (risk taking, boldness, selfreliance) (du Gay, 1996; Keat and Abercrombie, 1990; Miller and Rose, 1990; 1992) to create certain largely unquestioned effects (innovation, profit, acquisition, ownership). From within such discursive alignments organization becomes flatter, leaner and less 
bureaucratic, better able to hug close to free market winds. Enterprise becomes a form of structured, managed independence by which commercial and technological innovation is underscored by logics of de-regulation, heightened competitive performance and economic and social de-regulation couched in a language of material resuscitation and growth.. Enterprising people become themselves flesh-and-blood opportunities, and their curiosity and inquiry move like regular, linear piston strokes, driving them toward calculated returns (Anderson and Warren, 201 I; Jones and Spicer, 2005; McNay, 2009).

All sectors of society are touched: fire-services to hedge fund trading; foreign aid to health care; higher education to organic farming, and it seems, entrepreneurship studies. So prevalent is the association of enterprise and entrepreneurship they have become synonyms, even in studies purporting to gain critical on enterprise discourses (du Gay, 2004; Jones and Spicer, 2005). What, though, if the entrepreneurial were more than a condition of constantly adjusting individuals, innovating adaptively (cf. Schumpeter's 'adaptive response', describing a non-entrepreneurial approach to change; Schumpeter, 1947)? What if we decoupled innovation and creativity from the opportunistic pursuit of economic rents and a willingness to make oneself available to do yet more with still less (Gleadle, Cornelius and Pezet, 2008)? To ask thus is to question the neo-liberal view of an eminently adjustable and productive human nature (McNay, 2009: 59), and to consider entrepreneurship as an experience of imaginative and creative action. Without any calculated awareness of what collective or social transformation yields, spilling over from the orthodox ways of doing things exposes entrepreneur and audience alike to possibility.

Studies of social entrepreneurship have begun to broach such questions. Typically discussions defining social entrepreneurship embrace concepts of blended 
value, double bottom line, and the like, with the social configured as a concern extended from the commercial. Miller et al. (2012: 630), for example, talk of compassion as being an additional quality associated with successful entrepreneurial behaviour (integrative thinking, commitment, etc.), and, in turn, how social activity can benefit from the efficiencies of enterprising activity. Yet recently a number of studies have considered social transformation the distinguishing mark of social entrepreneurship (Dodd, et al, 20 I I; Hjorth, 20 I3; Kania and Kramer, 20 I I; Martin and Osberg, 2007), not its capacity to learn from commercial businesses or vice versa, and that, for Zahra, Newey and Li (20।3: I42) this emphasis carries a long history "[C]lassical economic theory has long recognized social (societal) outcomes as key aims of entrepreneurship." They anchor this view in the scholar who opened up entrepreneurship studies in the 1900s - Joseph Schumpeter - by adding: "Schumpeter (1942) saw entrepreneurial ventures as allocators of social wealth."' (p. 143). Prompted by these studies we broaden the point by suggesting entrepreneurship to be primarily a social force, making social entrepreneurship into somewhat of a tautology.

We now turn to an empirical illustration that itself is deliberately entrepreneurial (viz which both questions that which is typically considered an opportunity leading to a venture, and asks what our own academic discourse of entrepreneurship theory/studies conceals): the Chinese artist Ai Weiwei's Sunflower Seeds project. If entrepreneurship is the process of being sensitive to prevailing norms and habits in ways that find in these constraints invitations to experiment through imaginative re-configuration, then there is a deep sympathy. Art also brings form to hitherto unknown activity, and "gives to airy nothing/A local habitation and name" (Shakespeare). 
Ai Weiwei's Sunflower Seeds

Ai Weiwei dissident, activist, artist, venture creator, finds himself increasingly at odds with the Chinese government's continued hegemony over political and social life sustained, cleverly, by a palliative policy of economic liberalization. As protests at arbitrary detention, restrictions on travel, and party and government corruption grow, so Weiwei's artistic projects multiply. There is little distinction between creative expression, craft, tradition, free speech, all of which are co-ordinated by an often freeforming organization of researchers, artisans, advisors, gallerists, social media, commentators and assistants.

Weiwei's artistic questioning of the nature of community, politics and social space find exemplary expression on October $12^{\text {th }} 2010$ in the spreading neatly of 150 tons of handmade porcelain sunflower seeds over the floor of the turbine hall in Tate Modern, London (cf Barnaby Martin (2013: 107). To accompany the exhibition the Tate also makes a film showing how the seeds came to end up in their massive building. The film follows Weiwei following the stages involved in making porcelain - crushing, washing, mixing, moulding, firing, painting, glazing, firing - as well as the wider activity associated with the setting in which the seeds are made (Jingdezhen, China) and transported to London.

"Thanks for painting so many seeds," Weiwei says to a young woman passing on the street of Jingdezhen, the small town 600 miles from Beijing that in the old days made all the porcelain for the emperors. -"No need to thank me," she replies, and adds, "After all I did earn some money." (12.20mins). Another person noted: "brings business" which is good since "there is nothing much to do here anymore. Basically a lot of people have gone bankrupt." (6.30min) -"How much effort did you put in?" 
Weiwei continues his questions to the young woman. "How much effort?" she pauses, "about 2000 to 3000 RMB." Nearly two thousand people have been involved, being paid slightly above standard rates (around $\$ I$ an hour). The makers, steeped in an ancient and often inscrutable language of making porcelain, willingly make the seeds. In the background large, water-powered hammers crushing stone into fine powder ingredients make a rhythmic sound, somewhat of a heartbeat for the body of jingdezhen diligently performing allotted tasks, skillfully. He asks an old lady how long she has been doing this. "More than 30 years," she replies. -" The seeds are all individually hand painted, distinct things forming part of a multitude, each a self-sufficient life, distinct amongst myriad self-similar lives. "They are all nice people," Weiwei remarks, referring to the inhabitants of Jingdezhen, "you feel like you might have to make some more or make some other kind of project which can meet their needs." $(12.48)$

"The quantity we made for Tate [ $100 \mathrm{~m}$ seeds] is already beyond imagination." ( I 3.0 I min) He speaks as a manufacturer, proud of having handled the quantitative challenge, and enjoying the preposterous nature of gathering so many seeds in one place. They took five years to create. Each life-like seed is made in an ancient way from hand-hewn rock pounded into a paste, moulded, fired at around I300c, then painted, and re-fired at 800c, polished and washed.

As a visitor to the Tate there is a generous, massive beauty to the flow of the seeds as they give way under your feet; these imperishable, hard objects made by the gestures of artisans, become a flow as you walk upon and then within them; they yield and then resist, a crisp sound edging each footprint. Politically, China is huge, the seeds are myriad. Productively, China is immense, the seeds are multiple. They convey the sheer weight and scale of the place, they belong to its sheer productiveness. Yet they 
are also undifferentiated, equal, democratic, millions of individually distinct voices linked virtually, easily and instantaneously in proximity to one another without any guiding authority. The public is here in this rhetorical expression, in its raw possibility, itself an overspilling. There is no message as yet, just a gently undulating grey sea of possibility, a speaking space from which further speech may take place. Grey, the colour of the seeds is uncommitted, neither one nor the other and so open to become. The seeds in their patient exuberance suggest a confined force.

Though approachable, the audience has to learn about the resonance of sunflower seeds, especially the western viewer. The seeds are wenwu, cultural relics, evocative of multiple readings, they tremble with meaning. They belong to an established symbolic language of Chairman Mao. Historically sunflowers were shown gathered in enveloping swathes around the base of the leader's central image, a sun feeding buoyant plants, a leader feeding his ripening people. And now Weiwei shows the seeds without need for a sun, an independent democratic mass, or maybe just as dead seeds, or as representations of seeds that can take root symbolically in this Western gallery. The seeds are also a reminder of the physical austerity suffered by the Chinese under Mao's reforms when hunger abounded. Sunflower seeds were sold on streets. The seeds were shared by people gossiping, creating community space using the only snack food available in near starvation conditions during 1960-70's. The seeds evoke a collectivity, a sense of belonging to one another, and compressed by authority. These conditions might still prevail, only now less obviously, and the seeds disclose a need for change by remaining closed, refusing to be managed.

Nor do they respond so willingly to Western norms. The seeds have arrived at the Tate as the culmination of an artistic venture, yet the venture does not stop with the Tate. There are $8 \mathrm{~m}$ spare seeds for the gallery to replace those that are inevitably 
taken away in the pockets and bags of visitors, the artistic expression over-spilling the gallery walls and working its way into people's homes there to be subject to conversation, the occasional glance, and perhaps then to be sold on Ebay; the venture keeps rolling. Such overspilling questions the role of the gallery itself, its curatorial authority is loosened somewhat, as is its role in guarding ostensibly valuable works of art; how to deal with an art work that encourages visitors to take it away with them, to be so generous in its presence as to invite the audience to diminish it. Barely eight days into the exhibition the seeds are fenced off, the minute ceramic dust generated from walking upon the seeds is deemed a possible cause of chronic silicosis, a risk the workers of jingdezhen have faced continually, for generations. The fence allows the Tate to stop people taking the seeds, at the cost of diminishing the work of art. By April 201। Weiwei is also fenced off, deemed by Chinese authorities a risk to party, state and country, he is detained for 81 days. A ton of the seeds were sold at Sotheby's New York in May 2012 for $\$ 782,000$.

\section{Discussion}

Sunflower Seeds creates jobs for assistants, artisans, transport workers, gallery owners, commentators and guards. As an event of provocation it propels him as brand into the higher echelons of the art economy where significant sums are earned. The inventive occupation of gallery space distinguishes him as a creative force, he is technically proficient in working the art markets, he is himself a willingly productive being. Economic value and material gain are important aspects of his projects. In a classic sense, he is enterprising.

Yet the seeds' transformative power extends beyond the economic. They suggest China can do better than merely produce things for the rest of the world; it can 
experience civic freedom and the work in jingdezhen can become part of this: entrepreneurship is social change. He is influenced by his poet fathers' revolutionary spirit and those others committed to creating the kind of civic life first envisaged by Mao and his friends, before power got in the way. He speaks well of China, then suspiciously, a suspicion extended to the West because it too is woven into the practical and spiritual fate of China, something an artist is well-equipped to reveal: "We all of us somehow have to be honest enough to face our condition and of course the artist always, always is the one who recognizes a certain reality kind of early and tries to announce it ... They hear a kind of voice or they see some possibilities so clearly. But that all comes from the inner core, from the kind of nature they have. If there is anything valuable then it comes out because their nature perfectly reflects everybody's nature or instinct at that time" (in Martin, 2013: 189). Through questioning Sunflower Seeds discloses possibility, it reveals conditions, but speculatively and provocatively, both during the making of the work (where Weiwei is often unsure how 'it' will end up) and its being shown. Its transformative impact does not centre on economy or commerce, but effectively multiplies into social, political, aesthetic, cultural processes, all needed to make social change happen.

Here the entrepreneurial is primarily social as it potentially transforms the relations we have with institutional facts. Can we take from galleries? Do galleries or China or individuals have rights in property? Why are large quantities impressive and do they destroy individuality? Where do a piece of art start and a case of entrepreneurship stop? Is the revitalization of Jingdezhen the result of this work, and the Tate exhibition a mean? Such questions arise like tactical insinuations into habits and norms in ways that stretch, test and upset them, making visible through investigation what was hitherto overlooked, or accepted. Sunflower Seeds is loosening of the already organized and an 
incision (entre) holding open the possibility of differently configured relations with things we might take (preneur), persuaded by the performance to work beyond our norms awhile. It reveals how entrepreneurs can make others passionate in order to feed off them, working on their energy and willingness to participate and creating awareness of transformative potential. There is no scripted end point, no known output. Instead we have a serial interest in creating and sustaining fertile social spaces.

It would be prioritising a particularly poor understanding of Sunflower Seeds had we focused on its commercial sides; we might have grasped its enterprise aspect, not much more. By pushing into the social we find that entrepreneurship provokes by relating the economic and the social (and cultural, political and aesthetic) in an indecisive way - a multiplicity that loosens the ossified condition of things (Zahra, Newey and Li, 20 I3). Learning from cases like Sunflower Seeds we are thus exposed to possibility that springs from the social understood as a giving over to generosity; the work itself overspills the boundary of the cultural institution of the museum, the boundary of state authority, the boundary of ownership, but without providing a ready answer or end point. It creates in those involved a sense of possibility, nothing more, and it is this willingness to step back from outcomes that we feel exemplifies the entrepreneurial as distinct from enterprise, a willingness to work without a firm sense of what can be gained. This is the nature of the social an opening up, and any individuation, a closing off, erodes the entrepreneurial, posing the question whether enterprise can only ever set out to exploit, never create.

\section{References}

Anderson, A. and Warren, L. (20I I). 'The entrepreneur as hero and jester: Enacting the entrepreneurial discourse'. International Small Business Journal, 29(6): 589-609.

Campbell, K. (2004) "Quilting a feminist map to guide the study of women 
entrepreneurs, in Hjorth, D. and Steyaert, C. (Eds.) Narrative and Discursive approaches in Entrepreneurship, Cheltenham: Edward Elgar.

Dodd, S., Jack, S., Anderson, A. (20I3). 'From admiration to abhorrence: The contentious appeal of entrepreneurship across Europe'. Entrepreneurship \& Regional Development, 25(I-2), 69-89.

du Gay, P (1996) Consumption and identity at work. London: Sage.

du Gay, P. (2004). 'Against enterprise (But not against "enterprise", for that would make no sense)'. Organization, II (I), 37-57.

Erkkila, K. (1996). 'Enterprise Education in the Case of Finland'. Paper presented at the $9^{\text {th }}$ World Congress of Comparative Education Societies (Sydney, Australia, July 1996).

George, G., McGahan, A., and Prabhu, J. (2012) Innovation for inclusive growth:

Towards a theoretical framework and research agenda', Journal of Management Studies, 49(4), 66|-683.

Gleadle, P., Cornelius, N, and Pezet, E. (2008). 'Enterprising selves: How Governmentality meets agency'. Organization, I5(3), 307-313.

Hjorth, D. (2003) Rewriting Entrepreneurship - for a new perspective on organizational creativity, Malmö/Copenhagen/Oslo: Liber/CBS Press/Abstrakt.

Hjorth, D. (2013) "Public Entrepreneurship - Desiring Social Change, Creating Sociality", Entrepreneurship and Regional Development, 25(I-2): 34-5I.

Jones, C. and Spicer, A. (2005). 'The sublime object of entrepreneurship'. Organization, 12(2), 223-246.

Kania, J. and Kramer, M. (20I I) "Collective Impact," Stanford Social Innovation Review, Winter, pp. 36-4I.

Keat, R. and Abercrombie, N. (Eds.) Enterprise Culture, New York: Routledge.

Kenny, K., \& Scriver, S. (2012). Dangerously empty? Hegemony and the construction of the Irish entrepreneur. Organization, 19(5), 615-633.

Martin, B. (2013) Hanging Man: The Arrest of Ai Weiwei, New York: Faber and Faber.

Martin, R. L. and Osberg, S. (2007). "Social Entrepreneurship the case for definition," Stanford Social Innovation Review, Spring: 29-39.

McNay, L. (2009). 'Self as Enterprise: Dilemmas of control and resistance in Foucault's The Birth of Biopolitics'. Theory, Culture \& Society, 26(6), 55-77.

Miller, P. and Rose, N (1990) "Governing economic life", Economy and Society, 19(I): $|-3|$.

Miller, T., Grimes, M., McMullen, J., Vogus, T. (20I2) Venturing for others with heart and head: Compassion encourages social entrepreneurship', Academy of Management Review, 37(4): 616-640. 
Schumpeter, J. A. (1947 [199|]). 'The creative response in economic history'. In R. V. Clemence (ed.) Joseph A. Schumpeter: Essays. London: Transaction Publishers. 22I231.

Ure, O. B. (20।0) 'Formal education in an informal Norwegian culture of enterprise training - six cases collected from maritime and offshore environments', Country report from Norway to subproject 4 of Lifelong learning, sixth Framework programme, Fafo.

Zahra, S, and Newey, L. (2009). 'Maximizing the impact of Organization Science: Theory building at the intersection of disciplines and/or fields', Journal of Management Studies, 46(6), 1059-1075 